\title{
ESTRATÉGIA DE VIVER A VIDA DE UMA TRABALHA- DORA EXPATRIADA À LUZ DA ESTRATÉGIA EXISTEN- CIAL CONSUMISTA ${ }^{1}$
}

\section{Aline Mendonça Fraga ${ }^{2}$ \\ Vanessa Amaral Prestes ${ }^{3}$ \\ Carmem Ligia lochins Grisci ${ }^{4}$}

Resumo: $O$ presente estudo toma peculiaridades relativas ao gênero na especificidade da expatriação, à luz da estratégia existencial consumista. Trata-se de uma pesquisa qualitativa que se utilizou da entrevista narrativa como dispositivo de produção e análise. Os dados foram analisados à luz do referencial teórico vindo a comporem a narrativa construída no processo de análise. Os resultados apontaram para uma estratégia de viver a vida pautada na incorporação de um modo de ser e agir conforme a ordem masculina. A estratégia de viver a vida caracterizada se viu exacerbada em condição de expatriação, sustentando a estratégia existencial consumista.

Palavras-Chave: Gênero; Expatriação; Estratégia de viver a vida.

Abstract: The present study takes peculiarities related to the gender in the specificity of the expatriation, regarding the existential consumerist strategy. It is a qualitative research which used the narrative interview as a device of production and analysis. The data were analyzed according to the theoretic referential coming to compose the narrative constructed in the process of analysis. The results pointed to a strategy of living life guided by the incorporation of a way of being and acting in accordance to the masculine order. The strategy of living life characterized was exacerbated in an expatriation condition, sustaining the existential consumerist strategy. Keywords: Gender; expatriation; strategy of living life.

\section{Introdução}

presente estudo toma peculiaridades relativas ao gênero na especificidade da expatriação, à luz da estratégia existencial consumista. Parte-se do

\footnotetext{
1 Agradecemos à Capes e ao CNPq pelo apoio financeiro.

2 Doutoranda em Administração, Universidade Federal do Rio Grande do Sul (PPGA/UFRGS). E-mail: alinemf. adm@gmail.com

3 Mestre e Doutora em Administração (PPGA/UFRGS). E-mail: vanessa.amaral.prestes@gmail.com

4 Doutora em Psicologia, professora titular no Programa de Pós-Graduação em Administração na Universidade Federal do Rio Grande do Sul (PPGA/EA/UFRGS), Pesquisadora Produtividade em Pesquisa CNPq - 1D (302978/2014-

3). E-mail: carmem.grisci@ufrgs.br
} 
entendimento de que a sociedade líquido-moderna é uma sociedade de consumidores, na qual os indivíduos são, ao mesmo tempo, convocados a consumir e a transformarem-se em mercadorias vendáveis. Ela se "mantém em curso como uma forma específica de convivio humano, enquanto ao mesmo tempo estabelece parâmetros específicos para as estratégias individuais de vida que são eficazes e manipula as possibilidades de escolha e conduta individuais" (BAUMAN, 2008, p. 41).

$O$ investimento em si visibiliza a vendabilidade por meio do empenho em "obter qualidades para as quais já existe uma demanda de mercado, ou reciclar as que já se possui, transformando-as em mercadorias para as quais a demanda é criada" (BAUMAN, 2008, p. 75). O indivíduo deve, portanto, estar continuamente remodelando e reinventando sua vida na perspectiva da estratégia existencial consumista, que se vê encorajada à medida que pessoas aparentemente distintas são impelidas a se colocarem no mercado como produtos desejáveis para o consumo.

Ao movimentar-se entre o consumo e o esforço para fazer de si uma mercadoria vendável, o indivíduo - homem ou mulher - abandonaria com facilidade a vida vivida e o jeito de ser com a mesma prontidão se entregaria e se disponibilizaria para o que está por vir. Nessa perspectiva, manter-se como uma mercadoria vendável se constitui como a estratégia existencial consumista para levar a vida na sociedade de consumo, e o corpo é um dos lugares que mais recebem investimentos em prol da vendabilidade (BAUMAN, 2007; 2008). Essa configuração "representa o tipo de sociedade que promove, encoraja ou reforça um estilo de vida e uma estratégia existencial consumista" (BAUMAN, 2008, p. 71). Há de se considerar, entretanto, que essa questão envolva particularidades relativas ao gênero.

Por gênero compreende-se a interligação entre: "(1) um elemento constitutivo de relações sociais baseadas nas diferenças percebidas entre os sexos, e (2) uma forma primária de dar significado às relações de poder" (SCOTT, 1995, p. 86). A autora expande a teorização ao considerar o gênero como um campo no qual, ou por meio do qual, o poder se articula, interferindo nas relações sexuais e sociais. Associa-se gênero ao conjunto da vida que deve ser consagrado a gerenciar a empregabilidade individual, vendo-se esse conjunto como contabilidade existencial, em que "o curriculum vitae deve descrever com precisão a contabilidade de suas qualificações, de suas formações e de seus desempenhos, a fim de permitir aos empregadores medir com precisão o capital-competência" (GAULEJAC, 2007, p. 185).

Nesse sentido, toma-se a expatriação como campo pertinente ao estudo, dado que o crescimento das operações internacionais das empresas não foi acompanhado por um crescimento proporcional do número de homens e de 
mulheres ocupantes de posições no exterior. Internacionalmente, inclusive, as pesquisas acadêmicas assumem que as mulheres são preteridas nas expatriações em relação aos homens em face da já reconhecida discriminação de gênero presente nas empresas (ALTMAN; SHORTLAND, 2008; SHORTLAND, 2014; NUNES; CASACA, 2015). Por expatriação compreende-se "o processo de transferência de um profissional de uma empresa, sediada num país, para trabalhar, por tempo determinado ou não em uma unidade desta empresa ou grupo localizada em outro país" (FREITAS, 2000, p. 20).

Diante disso, julgou-se pertinente indagar: que estratégia de viver a vida se configura sob a ótica de uma mulher expatriada à luz da estratégia existencial consumista? Objetivou-se apresentar tal estratégia de viver a vida empreendendo-se uma pesquisa qualitativa que se utilizou da entrevista narrativa como dispositivo de produção e análise (JOVCHELOVICH; BAUER, 2017). Dadas suas características condizentes com a literatura relativa à expatriação, elegeu-se uma mulher que contemplasse a vivência da expatriação como um marco em sua trajetória profissional.

\section{Expatriação, estratégia existencial consumista e particularidades de gênero}

\subsection{Contexto de expatriação}

A expatriação pode ser entendida "pela sua raiz etimológica latina (ex patria, "fora da pátria"), afeta a todos os indivíduos que residem temporária ou permanentemente em um país diferente daquele onde nasceram" (GONZÁLEZ; OLIVEIRA, 2011, p. 1123). Expatriados e expatriadas são caracterizados na literatura de management como profissionais enviados ao exterior pelas empresas em que trabalham por um período de tempo variável (GALLON; FRAGA e ANTUNES, 2017; FREITAS, 2000).

A expatriação é condizente com a ideia da mobilidade como norma (GAULEJAC, 2007), e quem "não tem potencial para a mobilidade" (FREITAS, 2009 , p. 83) pode ficar de fora desse novo cenário que afeta os modos de trabalhar e de viver, pois

implica na exigência de adaptação constante às novas demandas do saber; na aprendizagem de outros códigos culturais; no respeito ao novo e ao diferente; na integração de diferentes e simultâneas experiências à sua biografia; no desenvolvimento constante do gosto pela aventura e pela novidade; na convivência pacífica e produtiva com a ambiguidade e a incerteza; na disponibilidade psicológica à mobilidade como forma de vida e; na constru- 
ção de múltiplas fontes de filiação e identidade (FREITAS, 2008, p. 83).

Em contexto de expatriação, as pessoas se veem imersas em um cotidiano rodeado de interações inesperadas e exigentes de um novo modo de viver e pensar a vida. Prestes, Grisci e Fraga (2016) indicaram que trabalhadores e trabalhadoras em contexto de expatriação inventam ou adaptam seus estilos de vida, em razão da vivência internacional acarretar constante desestruturação e reestruturação de si, corroborando Joly (2009).

Vivenciar e adaptar-se ao novo meio social demanda que se estabeleçam relações de alteridade para aproximação com a realidade local e compreensão de suas especificidades culturais (JOLY, 2009; MACHADO; HERNANDES, 2004). A adaptação cultural, parte importante da vivência de expatriação, é entendida como a "construção de um novo quotidiano e os ajustes feitos para reduzir as inseguranças e o mal-estar derivados do desconhecimento e da ignorância culturais, bem como a aceitação relativamente confortável do que é diferente naquelas novas circunstâncias e naquele código cultural" (FREITAS, 2010, p. 691).

Para Freitas (2009, p. 249) "a glamourização da mobilidade profissional é intencional, planejada, e visa estimular no indivíduo um imaginário viajante poderoso, transformando-o em um projeto individual de vida apenas". Quanto à mobilidade geográfica, apesar do glamour a respeito das carreiras internacionais ou globais, elas normalmente representam somente um periodo da trajetória profissional (GALLON; FRAGA; ANTUNES, 2017). Há de se considerar, inclusive, os muitos questionamentos a respeito dos resultados quando da repatriação e os indicativos de estagnação profissional ocasionado (GALLON; FRAGA; ANTUNES, 2017; GALLON; SCHEFFER; BITENCOURT, 2013; RODRIGUEZ e SCURRY, 2014), bem como a visão distorcida sobre os privilégios da mobilidade para mulheres expatriadas (RODRIGUEZ; RIDGWAY, 2018).

O local de trabalho, as atividades profissionais e as interações na rotina empresarial, por vezes, se tornam a principal referência na vivência da expatriação. Nesse caso, "um expatriado que priva da simpatia, da compreensão, da solidariedade e do acolhimento de seus colegas certamente terá mais condições de enfrentar as ondas de inseguranças que fatalmente virão" (FREITAS, 2010, p. 701). Homem e Dellagnelo (2006) constataram que é no local de trabalho que expatriados e expatriadas sentem maior segurança, já que este é um dos poucos elos de ligação que mantém com o país de origem, exceto nos casos em que viajam com a família. Questões a respeito da família que acompanha a pessoa expatriada são estudadas, pois o equilíbrio trabalho-vida pessoal no exterior se apresenta de forma bastante distinta do 
trabalho local (CALIGIURI; LAZAROVA, 2002; PEREIRA; PIMENTEL; KATO, 2005).

Sabe-se que, mundialmente, mulheres representam apenas $20 \%$ das pessoas expatriadas (BROOKFIELD GLOBAL RELOCATION SERVICES, 2014). Na contramão, "ao mesmo tempo que as empresas limitam a participação de mulheres em processo de expatriação, tendem a considerar a experiência internacional como requisito fundamental para a progressão profissional" (NUNES; CASACA, 2015, p. 90).

A literatura internacional sobre expatriação, há mais de 30 anos, aborda as disparidades entre os sexos nas experiências no exterior. Contudo, a discussão pouco avançou para além dos mitos relacionados às razões pelas quais as mulheres são preteridas em oportunidades no exterior (ADLER, 1984a, 1984b, 1984c); às barreiras que as organizações impõem à participação das mulheres em expatriação (FESTING; KNAPPERT; KORNAU, 2015; SELMER; LEUNG, 2003a); aos comparativos sobre sucesso e falha de homens e mulheres durante a experiência no exterior e às diferenças com relação ao sexo na adaptação cultural (CALIGIURI; LAZAROVA, 2002; HASLBERGER, 2010; SELMER; LEUNG, 2003b).

Estudos têm reconhecido uma segunda camada para o teto de vidro na discutida discriminação de gênero na gestão (ALTMAN; SHORTLAND, 2008; INSCH; MCINTYRE; NAPIER, 2008). A entrada das mulheres nos mercados tipicamente masculinos se dá, portanto, por necessidade de mão de obra. Em um momento em que o cenário internacional não tem mais a mesma atratividade inicial para os homens, essa é, de certo modo, uma "vitória vazia" que preenche "castelos vazios" (JHOFBAUER; FICHMAYR, 2004; KOLINGER, 2005).

A relutância das empresas, velada ou não, quanto à transferência de muIheres para o exterior, por vezes, é antecipada pela pré-determinada não-aceitação da mulher como gestora no país de destino, ou pela dominância de aspectos sexistas característicos de algumas culturas. Estudos apontam que, no exterior, primeiramente, a mulher é vista como "uma pessoa estrangeira" que ocupa um cargo superior. Somente com o passar do tempo passa a ser vista como uma mulher. Compreende-se que, a depender da base de poder, a questão de gênero pode ser tomada como menos relevante (ADLER, 1984a, 1984b, 1984c, 1987).

Com base em experiências de expatriadas compreendidas como "bem-sucedidas", Janssens, Cappellen e Zanoni (2006) ressaltaram a forma de interagir como "mulher", "gestora" e "expatriada ocidental". Ao darem atenção ao que as aproxima ou distancia de cada um desses papéis, as mulheres se deparam com uma construção particular que, estrategicamente, as coloca em 
posição de vantagem, conforme a ocasião.

Ver o sucesso como algo que as expatriadas 'fazem', mais do que uma carac-
terística pessoal natural, abre a possibilidade de ensinar e aprender como ser
bem-sucedida. A preparação para missões internacionais incluiria o desen-
volvimento de competências interculturais, não apenas em termos de apren-
der sobre a cultura anfitriã e comunicação intercultural, mas também apren-
der a como interpretar interações e detectar possibilidades de como agir
diante delas de uma forma que produza mais resultados positivos para si mes-
mas (JANSSENS; CAPPELLEN; ZANONI, 2006, p. 21 - tradução livre).

Em estudo sobre expatriadas organizacionais brasileiras, Fraga (2015) observou que as trajetórias foram ancoradas na construção da figura de "um profissional", envolto de um saber portar/agir no trabalho que preferencialmente deveria estar pautado no modo de "ser homem", intercalado com aspectos do "ser mulher", conforme o momento demandasse. $O$ ato de portar-se como "um profissional feminino" (ADLER, 1984a), é tido como uma vantagem, desde que explorado da forma correta, ou seja, estrategicamente. Assim, as ditas características do "modelo ideal de expatriado" - uma pessoa sensivel, conciliadora e com capacidade de ouvir (TUNG, 1995a, 1995b, 2004), são consideradas como um diferencial para as mulheres expatriadas.

\subsection{Vida líquida e estratégia existencial consumista}

Vida líquida é aquela em que as "pessoas dominam e praticam a arte da 'vida líquida': aquiescência à desorientação, imunidade à vertigem, adaptação ao estado de tontura, tolerância com a falta de itinerário e direção, e com a duração indefinida da viagem" (BAUMAN, 2007, p. 10), uma vida que se considerou similar à de expatriado.

A compreensão sobre a vida em época de globalização leva a considerar, conforme Rolnik (1997, p. 19), que as "identidades locais fixas desaparecem para dar lugar a identidades globalizadas flexiveis que mudam ao sabor dos movimentos do mercado e com igual velocidade". No jogo da vida líquida, as regras sempre mudam no decorrer da partida, e a estratégia mais indicada é manter o jogo curto, não se amarrar a lugares, não destinar a vida para uma só vocação, não oferecer garantias de coerência e lealdade. Ainda, ressalta-se que "o ponto central da estratégia de vida pós-moderna não é a construção de identidade, mas a evasão de se fixar", conforme alertou Bauman (2011, p. 123). As estratégias vencem rapidamente, sem tempo para projetar uma vida uniforme, que não contemple mudanças constantes. 
Mostra-se pertinente, portanto, voltar-se aos desafios com os quais se deparam as pessoas em busca de seus objetivos, desafios esses que influenciam "a maneira como estes tendem a viver suas vidas" (BAUMAN, 2007, p. 10). É preciso considerar que a estratégia de viver a vida poderá resultar tanto em "vidas despedaçadas, em estratégias partidas" (BAUMAN, 2011, p. 101), como na expansão da vida.

A estratégia existencial consumista é compreendida como aquela que alicia, estimula ou força pessoas a se produzirem como mercadorias atraentes e desejáveis que "fazem o máximo possivel e usam os melhores recursos que têm à disposição para aumentar o valor de mercado dos produtos que estão vendendo. $\mathrm{E}$ os produtos que são encorajadas a colocar no mercado, promover e vender são elas mesmas" (BAUMAN, 2008, p. 13).

Devido ao trabalho ser, na maioria das vezes, exercido distante do ambiente familiar e dos contatos próximos, considera-se que expatriadas se tornam gestoras de si (GAULEJAC, 2007). Nesse contexto que oferece liberdade, mas que exige disponibilidade permanente para o trabalho, as expatriadas podem se colocar em tensão, em contradição com seus próprios desejos. Podem investir, cada vez mais, em estratégias que exigem um produzir-se contínuo. Essa produção não é individual, ela se pauta em uma cultura comum que as chama a investirem em si mesmas para manterem-se empregáveis (GORZ, 2005), contando com o agravante de circularem um espaço predominantemente masculino como o da expatriação organizacional.

Tais constatações alcançariam, de um modo sem precedentes, o coletivo, embora com singularidades que mereçam atenção. Dessa forma, surgem indagações em relação a como se apresentariam questões de gênero no cotidiano da vida vivida na sociedade líquido-moderna.

\subsection{Trajetórias de mulheres: caminhos demarcados por questões de gênero}

Desde a sua origem, o conceito de gênero tem como proposta trazer uma categoria de análise que leve em conta a perspectiva das mulheres, historicamente excluidas de um mundo onde a ordem masculina imperou e impera até hoje (SCOTT, 1995). Fato é que não são as diferenças biológicas entre os sexos que determinam as desigualdades encontradas nas mais diversas esferas da vida das pessoas, mas sim a construção social de diferenciações sexuais.

Os processos de socialização são substancialmente generificados e se institucionalizam por normas sociais e culturais que atribuem determinadas características às mulheres e ao "modo de ser feminino". Assim, no que se refere ao exercício profissional, o conceito de respeitabilidade feminina, na maioria das vezes, não combina com a ideia da mulher que trabalha elou se 
movimenta em razão de trabalho (FERNANDO; COHEN, 2011). Outrossim, relaciona-se à mulher como responsável pelo cuidado da casa e dos filhos (LEUZE; STRAUß, 2016).

Nas discussões acerca de gênero, emergidas nos anos 1980, tomou forma o entendimento de masculinidade hegemônica, com relação direta ao poder na sociologia política. O termo foi compreendido como "um padrão de práticas (i.e., coisas feitas, não apenas uma série de expectativas de papéis ou uma identidade) que possibilitou que a dominação dos homens sobre as mulheres continuasse" (CONNELL; MESSERSCHMIDT 2013, p. 245).

Por conseguinte, entende-se que, embora as relações de gênero sejam históricas, as hierarquias de gênero são suscetiveis a mudanças, conferindo uma indicação positiva de que é possivel modificar a ordem. Connell (2018) considera que o foco do olhar para as masculinidades deve estar nos processos e nas relações sociais por meio das quais as pessoas conduzem suas vidas de forma generificada. As relações de gênero, entendidas como processos e práticas entre pessoas constituem uma das maiores estruturas das sociedades. De tal modo, é fundamental analisar as práticas das mulheres diante das arenas (re)produtivas de gênero. Elas são centrais em muitos processos que formam e mantêm locais de masculinidades como as mães, colegas de escola, namoradas, parceiras sexuais, esposas, colegas de trabalho, perante a segmentação do mercado de trabalho, entre outras formas. Destaca-se, então, que "as pesquisas sobre masculinidade hegemônica agora precisam estar mais atentas às práticas das mulheres e à ação histórica de feminilidades e masculinidades" (CONNELL; MESSERSCHMIDT, 2013, p. 265).

modo de ser, socialmente considerado como masculino, foi parte fundamental na formação dos Estados modernos. Historicamente, entende-se que a militarização, o nacionalismo e a masculinidade caminharam juntos (OLIVEIRA, 2004). Força, disciplina, trabalho e ordem foram valores associados aos homens, especialmente em períodos de guerra e de luta. Em épocas de paz, o modelo "ideal do soldado viria agora a se juntar o ideal do trabalhador, do produtor de mercadorias e provedor: disciplinado, industrioso, responsável" (OLIVEIRA, 2004, p. 46).

Ora, se gênero é sempre relacional e os padrões de masculinidade são definidos na sociedade em oposição a algum modelo (seja real ou imaginário) de feminilidade (CONNELL; MESSERSCHMIDT, 2013), nesse caso, pode-se inferir que valores foram também estabelecidos como femininos. Pelos entendimentos expostos, compreende-se por que é tão importante que, em pesquisas sobre homens e masculinidades, seja reconhecida a posição assimétrica entre masculinidades hegemônicas e feminilidades enfatizadas (CONNELL; MESSERSCHMIDT, 2013), na medida em que elas acontecem jun- 
tas no processo histórico.

$\mathrm{Na}$ literatura internacional, há diversas pesquisas que exploram as maquiagens de gênero em profissões historicamente identificadas como masculinas ou femininas e, nesse caso, exigentes de uma postura condizente de masculinidades e de feminilidades. Fisher (2015) conta de que modo, a partir da crise de 2008, as "mulheres de Wall Street" passaram a ser consideradas como possiveis salvadoras da economia global. A crise financeira foi abordada em termos extremamente generificados, a partir de uma articulação que colocava de um lado a masculinidade, a ganância e as atitudes de riscos, e de outro a feminilidade, o conservadorismo e a aversão ao risco como um meio de superar a situação. $\bigcirc$ "estilo feminino" de liderança incorpora uma ordem que está dentro de um certo tipo de feminismo, e argumenta muito mais em favor da reprodução de um poder que está nas mãos de uma elite de homens e mulheres, do que em prol de uma quebra das estruturas desiguais de poder como um todo (FISCHER, 2015).

Em campos profissionais tradicionalmente ocupados por homens, é comum que as mulheres encontrem extrema dificuldade em receber credibilidade quando tentam equilibrar trabalho e vida pessoal. Além disso, é esperado um agir como homem, que inclui aceitar discriminações, alcançar uma reputação e adotar uma postura "anti-mulheres" (BUSSINGER; MENANDRO; PADILHA, 2017; FRAGA, 2015; HIRSHFIELD, 2015; POWELL; BAGILHOLE; DAINTY, 2009; WATTS, 2009). Corroborando esses aspectos, o estudo de Guillaume e Pochich (2009) argumenta que, implicitamente, a organização das carreiras internacionais evidencia que determinados postos de trabalho não são para mulheres. Complementarmente, Duberley e Cohen (2010) destacam que o comprometimento familiar, historicamente considerado como uma responsabilidade inerente às mulheres, pode ser visto como um sinal de maturidade e de responsabilidade para os homens. Por outro lado, o não comprometimento com a família é um indicativo de falta de compromisso para as mulheres.

Em relação à população expatriada, estudos apontam que a maioria é do sexo masculino, branco, anglo-saxão; trabalha em multinacionais como exe- 
cutivo e/ou gerente; preferencialmente é homem, ainda que isso não fique evidente (maquiagem de gênero); têm qualificação técnica/educacional; recebe altos salários, benefícios e suporte organizacional (ADLER, 1984a; SHORTLAND, 2014; KOLLINGER, 2005; HUTCHINGS; FRENCH; HATCHER, 2008), o que justifica lançar o olhar sobre a vivência de uma trabalhadora expatriada à luz da estratégia existencial consumista.

\section{Procedimento Metodológico}

A fim de responder ao objetivo proposto, que buscou entender a estratégia de viver a vida que se configura sob a ótica de uma mulher expatriada à luz da estratégia existencial consumista, realizou-se uma pesquisa qualitativa, que se utilizou da entrevista narrativa como dispositivo de produção e análise (JOVCHELOVICH; BAUER, 2017). O percurso metodológico da pesquisa iniciou por meio da escolha de uma expatriada com vivência em expatriação, dentre integrantes de uma rede de brasileiros e brasileiras expatriadas. A entrevistada foi Maria, cujo nome fictício lhe foi a fim de garantir-lhe o anonimato. Trata-se de uma mulher trabalhadora, de 56 anos, mãe de dois filhos adultos e pós-graduada em dois cursos. À época da entrevista, ocupava um cargo gerencial e havia retornado recentemente de uma experiência de expatriação para a Índia, com duração de mais de quatro anos. Elegeu-se a participante dadas as suas características condizentes com a literatura relativa à expatriação, e tendo em vista que a vivência profissional no exterior foi considerada um marco em sua trajetória profissional.

Seguindo orientações de Jovchelovich e Bauer (2017), a entrevista foi realizada buscando compreender as fases indicadas para tal tipo de pesquisa. São elas:

i) Preparação e exploração do campo: formulação de questões exmanentes.

ii) Iniciação e formulação do tópico inicial para narração: emprego de auxílios visuais (opcional).

iii) Narração central: nessa fase recomenda-se a não interrupção da fala da pessoa entrevistada; o encorajamento não verbal ou paralingüístico que estimule a narração; e a espera de para sinais de finalização da narração.

iv) Fase de perguntas: recomenda-se somente perguntas do tipo "que aconteceu então?"; não dar opiniões ou fazer perguntas sobre atitudes; não discutir sobre contradições; não fazer perguntas do tipo "por quê? "; ir de perguntas exmanentes para imanentes.

v) Fala conclusiva: fase na qual se para de gravar, e na qual são permitidas 
perguntas do tipo "por quê"? Indica-se a produção de anotações imediatamente depois da entrevista.

Levantaram-se os pontos chamados exmanentes a partir da aproximação com o campo e com a leitura do referencial teórico pertinente ao estudo. Foi solicitado que Maria, primeiramente, contasse sua trajetória de vida desde a infância, passando por suas escolhas e renúncias pessoais elou profissionais até chegar no momento da expatriação. Por fim, Maria relatou a experiência no exterior e o caminho percorrido até o momento da entrevista. A partir de sua própria narrativa da participante, buscaram-se os pontos imanentes que possibilitaram produzir a análise da narrativa.

A entrevista narrativa, com duração aproximada de 2 horas, foi a técnica de coleta de dados utilizada. Gravada com autorização da entrevistada para posteriormente ser transcrita e analisada, a entrevista foi realizada após o expediente em seu local de trabalho. Ao final da entrevista, Maria comentou que "mal viu o tempo passar", e que contou sobre momentos e sentimentos vividos nunca antes relatados até mesmo para pessoas próximas ou de sua família. A entrevista transcrita foi enviada para sua validação, dada a solicitação da empresa na qual trabalha. Os dados coletados foram analisados à luz do referencial teórico pertinente, vindo a compor narrativas acerca da trajetória de Maria.

\section{A estratégia de viver a vida à luz da estratégia existencial consumista: um olhar sobre gênero}

\subsection{A Trajetória de Maria}

De família de classe média baixa, Maria comentou que, na sua época escolar, o estudo máximo equivalia ao atual ensino médio. "E depois você se prepara para casar e viver feliz para sempre". Maria contou que começou a trabalhar aos 11 anos, informalmente. Aos 13 já era empregada em uma loja no interior do estado de São Paulo. Sua trajetória profissional começou a tomar forma em 1978, aos 19 anos, quando foi trabalhar em uma multinacional americana. Por ter iniciado no setor de exportação, estudou inglês e decidiu cursar Administração com ênfase em Comércio Exterior.

De alguma forma o interesse em ter uma carreira no exterior estava "gravado no meu inconsciente", já que "o meu sonho era ser atriz, cantora, aeromoça". Entretanto, considera que foram dois homens, em especial, que deram um horizonte sobre o caminho a seguir, e esse caminho não se restringia às fronteiras do Brasil. 


\begin{abstract}
Um deles foi meu professor de inglês, que eu lembro até hoje que eu falava para ele que meu sonho era ser aeromoça, e ele me disse: - A tua cabeça é muito pequenininha, você precisa pensar fora da caixa, porque sendo aeromoça, você não passa de uma garçonete de um avião. E se você está fazendo uma faculdade, você está estudando, fazendo uma faculdade, pensa um pouco grande, e foi aí que eu comecei. E eu tive um colega de trabalho que me incentivou muito, e que me apoiou, inclusive, ele já viajava, e eu tomei como um referencial, e pensei que talvez, um dia, eu também começasse a viajar, tivesse essa oportunidade (MARIA, 2015).
\end{abstract}

Após passar por diversas empresas de exportação e importação, Maria cursou também a faculdade de Direito. Casou-se com um advogado, com quem teve dois filhos. Em 1995, surgiu a primeira oportunidade de viajar a trabalho, segundo ela, um objetivo comum a quem é da área de Comércio Exterior. Foi a única mulher a inscrever-se para a vaga conquistada. Em suas palavras, "alguns me diziam: 'como? Isso é um absurdo, uma mulher pelo mundo!". Suas atribuições estavam relacionadas aos contatos comerciais da empresa para a qual fora contratada - a maior concorrente da companhia para a qual trabalhava à época da entrevista, e pela qual foi expatriada.

Eu fui muito bem colocada nos testes, e não teve como dizerem não. E eu assumi a
vaga. Comecei viajando para países, por eu ser mulher me deram os piores lugares,
claro. Eera a única que falava inglês na empresa naquela época, então eu fiquei com os
países da África, do extremo Oriente. Mas o desafio valeu, porque eu apanhei muito
no bom sentido, para entender as culturas, entender como me comportar em uma
negociação, junto a clientes com culturas bem diferentes da nossa (MARIA, 2015).

A carreira na atual empresa começou em 2005. Alguns anos depois, ao saber que haviam acabado de adquirir uma empresa na İndia, vislumbrou novamente a possibilidade de vir a ser expatriada. "Aí eu recebi um corte daqueles - Ah, tu tá louca? Nunca que uma mulher vai ser expatriada para a Índia!". Maria relata que as pessoas "mal sabiam" que ela já havia estado "em locais bem hostis com as mulheres, como Líbano e Paquistão". Sobre isso, comentou: "me limitei a responder: "é um desejo, e quem sabe? Eu o estou jogando para o Universo".

A expatriação de Maria aconteceu de forma peculiar, quando um gestor responsável pela implementação da empresa na Îndia buscou indicações de pessoal do setor dela para envio ao exterior. "Buscavam alguém da minha área. Respondi: 'Acho que fulano'. 'Fulano não'. 'E que tal o sicrano?' 'O sicrano, também não'. E todos os que eu indicava simplesmente não serviam. $\bigcirc$ 
jeito foi dizer: 'se ninguém serve, então eu me candidato!'. Foi um "convite às avessas", já que a empresa nunca havia expatriado uma mulher e o local de instalação no exterior carecia de condições estruturais.

Para tal empreitada, Maria teve o apoio dos dois filhos, já adultos. "A reação deles, eles vibraram e me deram muito apoio. E eu lembro das palavras deles até hoje, me dizendo que essa experiência era o que faltava para complementar a minha carreira. Isso foi em junho, julho de 2009". O mesmo apoio não foi recebido pelo namorado, com quem terminou o relacionamento quando estava no exterior havia três meses. "Acabei abrindo mão em função da distância, da dificuldade de administrar a relação, e também pelo desdém que senti dele. Me deu a sensação de que ele duvidava da minha capacidade, coragem, resiliência e obstinação", disse ela.

Repatriada há pouco menos de dois anos, à época da entrevista, avaliava que foi uma das poucas pessoas da empresa que não quis ser expatriada almejando alguma expectativa de melhoria na carreira. "Fui pela ideologia e com a expectativa de conhecer a cultura". Conhecidos os principais acontecimentos da trajetória de Maria, pode-se vislumbrar a estratégia de viver a vida que se configurou na experiência de expatriação, conforme se apresenta a seguir.

\section{4 .2 Estratégia de Viver a Vida de Mulher Expatriada}

"Você não é uma mulher, você é um profissional. Um profissional não tem sexo enquanto ele estiver atuando profissionalmente". A sentença escutada de um diretor comercial e reproduzida por Maria, que a compreendeu como um conselho e um direcionamento da conduta a seguir, sustentou sua estratégia de viver a vida de expatriada. Ressalta-se que a expatriação de Maria remete à forma como as mulheres entraram no mercado de trabalho, nas carreiras organizacionais e, por fim, nas experiências de expatriação, preenchendo "castelos vazios" (HOFBAUER; FICHMAYR, 2004; KOLINGER, 2005).

Cabe esclarecer, de imediato, que restará claro que "um profissional não tem sexo enquanto ele estiver atuando profissionalmente", se for mulher, dada a insistência de que carreiras organizacionais não são para mulheres, conforme apontam Guillaume e Pochich (2009). Desse modo, Maria foi tratada como um profissional. "Eu não tive frescuras de mulher, privilégios por ser mulher. As pessoas do sexo masculino e eu, nós tínhamos os mesmos benefícios, usávamos o mesmo carro, as mesmas vantagens, tudo era igual". Até o banheiro, cabe esclarecer.

Condizente com a estratégia existencial consumista, observa-se que a história de Maria é marcada por empreendimentos individuais, um trabalho "do tipo faça-você-mesmo", um "dever individual" e reflete seu "investimento, seja 
ele genuíno ou suposto, anunciado de forma explícita ou indireta" (BAUMAN, 2008 , p. 75, grifo do autor). MAria produziu-se no "modo de ser" dos homens, afastando-se de outras mulheres ao não se enxergar como uma delas. "Pode ser que lá na frente, eu venha a me arrepender de não ter tido um casamento de novo, coisas que muitas mulheres têm e eu não tenho. Tá em tempo ainda? Tá em tempo, mas já ficou difícil, até pelo meu jeito de ser, porque querendo ou não, eu acabo assustando". Maria aproxima-se dos achados de Nunes e Casaca (2016) no sentido de que ainda é menor o número de acompanhantes homens em situação de expatriação. Como anunciado, a vida líquida enfatiza, do princípio ao fim, "esquecer, apagar, desistir e substituir" (BAUMAN, 2007, p. 9).

A vida de consumo, vivida na sociedade líquido-moderna, refere-se essencialmente e acima de qualquer circunstância, a estar em movimento (BAUMAN, 2008), por essa razão é uma vida que se considerou condizente com a vivida na expatriação. Maria ilustra essa condição de viver em movimento constante, quando relata que está tão acostumada "a estar aqui hoje falando contigo e amanhã, se tiver que ir para o México, eu vou. Arrumar minha malinha, fechar minha porta e tchau, benção". A estratégia demanda a recusa de fixar-se, por mais agradável que possa parecer o lugar em que se está (BAUMAN, 2011).

Um dos paises de destino da expatriada, a Índia é considerada um dos lugares que apresenta maior desafio para pessoas expatriadas (BROOKFIELD GLOBAL RELOCATION SERVICES, 2014) e um local em que a desigualdade de gênero alcança significativamente o mercado de trabalho (BATRA; REIO JR, 2016). Os colegas indianos de Maria consideravam "um absurdo que uma mulher viajasse por toda parte do país, sobretudo acompanhada por homens". Conforme contou, todas as quinze mulheres que trabalhavam em sua empresa compartilhavam dessa opinião. Connell (2018) alerta sobre como as próprias práticas das mulheres reforçam a masculinidade na interação entre masculinidades e feminilidades.

Como também alertado pela literatura, a vivência da expatriação pode exaltar a necessidade de construir outros entendimentos e outras formas de viver a vida, diferenciados do aprendido no país de origem, ainda que estes sejam levados consigo (FREITAS, 2010; JOLY, 2009; MACHADO; HERNANDES, 2004). A cultura da Índia reforçou a estratégia de viver a vida de expatriada previamente sentenciada. "A minha questão lá foi só essa questão de adaptação no começo que, também, depois, eu fui observar, não era só pelo fato de eu ser mulher, era uma reação normal da outra parte quando recebiam alguém de fora". Essa observação de Maria corrobora o que apontam os estudos sobre mulheres expatriadas, que são consideradas como "estrangeiras que venham a ser mulheres" (ADLER, 1984c, p. 86). A chegada 
de uma estrangeira provoca expectativas nas pessoas residentes do país de destino, já que a escolha por uma mulher para expatriação em detrimento de um homem possivelmente ocorreu pelo fato de ela ser extraordinariamente competente (ADLER, 1987).

Tentativas de impedimento ao trabalho de Maria foram notadas no fato de ela nunca ser convidada para as reuniões, tomar conhecimento delas no horário do seu acontecimento (quando tomava), de modo que ela "entrava e ficava múmia paralítica. Eu acho que fiquei uns seis meses, numa inércia total". Diante da expressão "múmia paralítica", a apontar-lhe o sedentarismo que the cabia, questiona-se, a exemplo de Freitas (2009, p. 249), acerca da sustentação do glamour e do "imaginário viajante poderoso". Maria também relatou que por estar em um cargo de coordenação e "precisar dar o exemplo para a equipe", privava-se de viagens, corroborando o estudo de Prestes, Grisci e Fraga (2016) que apresentam a experiência de expatriação como exigente de renúncias quando da adaptação ao estilo de vida no exterior.

Condizente com a vida líquida, que preza pela obsolescência, finais rápidos e indolores, Maria conta sobre o rompimento de um relacionamento amoroso com certo pesar "falei para ele que iria ficar [na Índia], que eu estava gostando, e que eu achava melhor terminarmos. Eu acho que foi a única coisa que depois eu meio que me arrependi um pouco, porque ele era uma pessoa importante para mim". Entretanto, na estratégia de viver a vida em movimento, como nesse caso, deixar ir mostrou-se um imperativo (BAUMAN, 2007).

Nessa mesma lógica, tomada de autoexame, autocrítica e autocensura (BAUMAN, 2008), em concordância com a insatisfação consigo carregada na vida líquida, Maria conta que ao aceitar a expatriação, considerada "o ápice" da sua carreira, outras renúncias foram necessárias. Em concordância com o estudo de Duberley e Cohen (2010), o comprometimento familiar para as mulheres pode resultar problemas profissionais para elas.

\footnotetext{
Você tem que estar muito certo disso, você tem que abrir mão, mão de educar teus filhos, de participar de reunião de pais e mestres, aniversários, formaturas, eu não vi a formatura do meu filho menor, eu estava na ĺndia. E eu levo essa culpa, estou trabalhando ainda para amenizar isso, mas eu levo isso, porque por mais que ir para a Índia era importante para mim, eu também sou mãe (MARIA, 2015).
}

Cabe ressaltar que Maria referiu a si na forma masculina, ao dizer "certo" e não "certa", apresentando-se de modo recorrentes como UM profissional. $\bigcirc$ uso reiterado das denominações no gênero masculino reforça a associação, seja ela de origem linguística ou cultural, do ser profissional como algo que ainda faz parte do universo do homem. Dessa forma, Maria lança mão de 
uma estratégia existencial consumista que contempla o uso de qualificações e intitulações correntemente aceitas e legitimadas em seu meio social, ainda que sejam em um gênero diferente do seu, remodelando a forma como vê a si mesma enquanto mercadoria para o mercado (BAUMAN, 2008). Por diversos momentos, Maria relaciona a ideia de feminilidade com e de respeitabilidade (CONNELL; MESSERSCHMIDT, 2013; FERNANDO; $\mathrm{COHEN}, 2011)$ com relação às outras mulheres, mas não a ela própria. Segundo ela é "comum que as mulheres de sua geração esperem o homem abrir a porta, pagar a conta, tomar iniciativa de tudo". Isso condiz com a postura anti-mulheres vital para àquelas que desejam um espaço no "mundo dos homens" (POWELL; BAGILHOLE; DAINTY, 2009; WATTS, 2009; FRAGA, 2015; HIRSHFIELD, 2015). Em relação às solicitações que as mulheres de sua equipe lhe faziam, Maria estranhava:

Eu estranhei uma coisa, dentro dos pedidos delas, é que elas queriam direitos iguais, mas, quando estivesse chovendo, a empresa tinha que disponibilizar um carro para levá-las da portaria para a fábrica, que era assim, tipo, $800 \mathrm{~m}$. Ah, mas eu fiquei muito feroz aquele dia. Como elas queriam direitos iguais, e vinham pedir um transporte da porta do escritório até a porta do ônibus, percebe? Por favor! (MARIA, 2015).

A fala de Maria revela que ela não se identificava com as mulheres de sua equipe. Há de se considerar que a base de poder (ADLER, 1984a, 1984b, 1984c, 1987; STONE, 1991) é sustentada pelo jeito que a mulher "faz seu sucesso" na expatriação (JANSSENS; CAPPELLEN; ZANONI, 2006), e pelo exercício da masculinidade (FISCHER, 2015; FRAGA, 2015; WATTS, 2009; HIRSHFIELD, 2015) para "conquistar o seu espaço".

Maria disse que "era muito mais 'faca na bota", que "brigava muito" pelo seu espaço, que "se posicionava". Tomou-se seu posicionamento como um modo condizente com a rentabilização de si espelhada em supostos modelos masculinos, a fim de incrementar sua vendabilidade, característica elementar da estratégia existencial consumista (BAUMAN, 2008).

O modo como Maria se revelava UM profissional, levava a questionamentos acerca de sua orientação sexual por parte de colegas de trabalho. "Quando eu comecei a viajar, uma colega perguntou se eu era sapatão. 'Por que você acha que eu sou sapatão?' Porque você fala como os homens, em igual com eles, e você me chamou de minha loira". Bussinger, Menandro e Padilha (2017) apontaram que mulheres heterossexuais tendem a associar características biológicas e psicológicas à masculinidade e à feminilidade, assim, comportar-se "como homem" pode romper com a identidade feminina. Outrossim, à observação que fizeram Nunes e Casaca (2015), a respeito de 
comentários sexistas feitas por homens frente a mulheres em lugares formais de decisão, acrescenta-se que também o fazem outras mulheres. Ao se portar visivelmente como UM profissional, Maria faz jus ao cargo que ocupa, aproximando-se dos homens e do modelo dito masculino, e se distanciando das mulheres e do modelo dito feminino.

\section{Considerações Finais}

caso em questão permite ver uma estratégia de viver a vida pautada na incorporação de um modo de ser e agir na ordem do masculino, evidenciando o tratamento da mulher expatriada como UM profissional. Esse modo se estendeu como demanda dirigida às demais mulheres que, com a participante do presente estudo, compartilharam o mesmo trabalho.

Considera-se que a estratégia de viver a vida se vê exacerbada em condição de expatriação, sustentando a estratégia existencial consumista. $O$ campo empírico do presente estudo contribui para a interligação da perspectiva de gênero à estratégia existencial consumista, uma vez que Maria também age em prol da vendabilidade de si. Deste modo, colabora para reforçar a escolha de um estilo de vida que coloca em pauta as particularidades relativas ao gênero, especialmente no que diz respeito ao esforço para se enquadrar nas características para as quais existe maior receptividade e espaço no contexto organizacional. Tais características que compõem esse estilo de vida são demandadas na condição de expatriação, visto que, no cenário internacional, mulheres são preteridas nas expatriações organizacionais.

Como contribuições do estudo, destaca-se a possibilidade de vislumbrar uma realidade que se apresenta em expansão, e de compreender que a vida que aguarda uma mulher expatriada no país de destino não é a mesma vida vivida no país de origem. A vida de expatriada há de ser vivida no sentido de contemplar a perspectiva de instantaneidade e de curto prazo, características da sociedade líquido-moderna. Assim como Bauman (2011) sugeriu que a melhor estratégia tem sido manter o jogo curto, sem planos em longo prazo, a estratégia de viver a vida de expatriada parece estar ancorada na tentativa de manter o equilíbrio entre oportunidades e riscos que a situação de expatriação abarca, especialmente para mulheres.

Considera-se a impossibilidade de generalização como um limitador do estudo. Entretanto, a relevância da narrativa analisada esteve em servir para a compreensão de particularidades. Nesse caso, a ênfase esteve na singularidade, o que abre espaço para reconhecer outros casos diferentes ou similares a esse. Para estudos futuros, sugere-se investigar a performance relativa à gênero e à sexualidade, com mulheres que não ocupam posições gerenciais, e 
também em espaços onde trabalham uma maioria de mulheres.

\section{Referências}

ADLER, N. J. Women do not want international careers: And other myths about international management. Organizational Dynamics, v.13, 1984a.

. Women in international management: Where are they?. California Management Review, v. 2, n. 4, 1984b.

Expecting international success: Female managers overseas. Columbia Journal of World Business, v. 19, n. 3, 1984c.

Pacific basin managers: A gaijin, not a woman. Human Resource Management, v. 26, 1987.

ALTMAN, Yochanan; SHORTLAND, Susan. "Women and international assignments: Taking stock - a 25-year review". Human Resource Management, v. 47, n. 2, p. 199-216, 2008.

BAUMAN, Zygmunt. Vida Líquida. Rio de Janeiro: Jorge Zahar Editora, 2007.

Vida para consumo: a transformação das pessoas em mercadoria. Rio de Janeiro: Jorge Zahar Editora, 2008.

Vida em fragmentos: sobre ética pós-moderna. Rio de Janeiro: Jorge Zahar Editora, 2011.

BATRA, Renu; REIO JR, Thomas G. Gender inequality issues in India. Advances in Developing Human Resources, v. 18, n. 1, p. 88-101, 2016.

BUSSINGER, Rebeca Valadão; MENANDRO, Maria Cristina Smith; PADILHA, Isadora Lee; Representações Sociais de Masculinidades de Mulheres Lésbicas e Heterossexuais. Revista Gênero, v. 18, n. 1, p. 259-279, 2017.

BROOKFIELD GLOBAL RELOCATION SERVICES (2014). Global Relocation Trends Survey. Estados Unidos, 2014. Disponivel em: <http://www.brookfieldgrs.com/wp/wp-content/uploads/toolbox.v.2/GMTS_2014-GMTS.pdf>. Acesso em: 01 abr. 2015.

CALIGIURI, Paula M.; LAZAROVA, Mila. "A model for the influence of social interaction and social support on female expatriates' cross-cultural adjustment". International Journal of Human Resource Management, v. 13, n. 5, p. 761-772, 2002. 
CONNELL, Raewyn W. Masculinities. Cambrige: Polity Press, 2018.

CONNELL, Robert W.; MESSERSCHMIDT, James W. Masculinidade hegemônica: repensando o conceito. Estudos feministas, p. 241-282, 2013.DUBERLEY, Joanne; COHEN, Laurie. "Gendering career capital: An investigation of scientific careers". Journal of Vocational Behavior, v. 76, n. 2, p. 187-197, 2010.

FERNANDO, Weerahannadige Dulini Anuvinda; COHEN, Laurie. "Exploring the interplay between gender, organizational context and career: A Sri Lankan perspective". Career Development International, v. 16, n. 6, p. 553-571, 2011.

FISHER, Melissa. "Wall Street women: professional saviors of the global economy". Critical perspectives on international business, v. 11, n. 2, p. 137-155, 2015.

FRAGA, Aline Mendonça. Trajetórias de mulheres expatriadas. 2015. $146 \mathrm{f}$. Dissertação (Mestrado Programa de Pós-graduação em Administração) - Programa de Pós-Graduação em Administração, Universidade Federal do Rio Grande do Sul, Porto Alegre, 2015.

FESTING, Marion; KNAPPERT, Lena; KORNAU, Angela. Gender-specific preferences in global performance management: An empirical study of male and female managers in a multinational context. Human Resource Management, v. 54, n. 1, p. 55-79, 2015.

FREITAS, Maria Ester de. "Como vivem os executivos expatriados e suas famílias? Relatório de Pesquisa", EAESP/FGVINPP, n 7, Núcleo de Pesquisas e Publicações, p. 1-117, 2000.

O\&S, v. 15, n. 45, abr/jun, 2008.

"A mobilidade como novo capital simbólico nas organizações ou sejamos nômades?" O\&S, Salvador, v. 16, n. 49, p. 247-264, Abr./Jun., 2009.

"Expatriação profissional: $O$ desafio interdependente para empresas e indivíduos". GES - Revista Gestão e Sociedade. CEPEAD/UFMG, vol. 4, n 9 , Set/Dez, 2010.

GALLON, Shalimar; FRAGA, Aline Mendonça; ANTUNES, Elaine Di Diego. CONCEITOS E CONFIGURAÇÕES DE EXPATRIADOS NA INTERNACIONALIZAÇÃO EMPRESARIAL. REAd-Revista Eletrônica de Administração, v. 23, p. 29-59, 2017.

GALLON, Shalimar; SCHEFFER, Angela Beatriz Busato; BITENCOURT, Betina Magalhães. "Eu fui, voltei e ninguém viu: um estudo sobre a expectativa de 
carreira após a repatriação em uma empresa brasileira". Cadernos EBAPE. BR, v. 11, n. 1, p. 128-148, 2013.

GAULEJAC, Vincent de. Gestão como doença social: ideologia, poder gerencialista e fragmentação social. São Paulo: Ideias e Letras, 2007.

GONZÁLEZ, Juan Miguel Rosa; OLIVEIRA, José Arimatés de. "Os efeitos da expatriação sobre a identidade: estudo de caso". Cadernos EBAPE. BR, v. 9, n. 4, p. 1122-1135, 2011.

GORZ, André. O Imaterial: Conhecimento, Valor e Capital. Annablume, 2005.

GUILLAUME, Cécile; POCHIC, Sophie. "What would you sacrifice? Access to top management and the work-life balance". Gender, Work \& Organization, v. 16, n. 1, p. 14-36, 2009.

HASLBERGER, Arno. Gender differences in expatriate adjustment. European Journal of International Management, v. 4, n. 1-2, p. 163-183, 2010.

HIRSHFIELD, Laura E. "I Just Did Everything Physically Possible to Get in There. How Men and Women Chemists Enact Masculinity Differently". Social Currents, v. 2 p. 324-340, 2015.

HOFBAUER, Johanna; FISCHLMAYR, Iris.C. "Feminization of international assignments: conquering empty castles?" International Studies of Management \& Organization, v. 34, n. 3, p. 46-67, 2004.

HOMEM, Ivana Dolejal; DELLAGNELLO, Eloise Helena Livramento. "Novas formas organizacionais e os desafios para os expatriados". RAE-Eletrônica, v.5, n.1, 2006.

HUTCHINGS, Kate; FRENCH, Erica; HATCHER, Tim. "Lament of the ignored expatriate: An examination of organizational and social network support for female expatriates in China". Equal Opportunities International, v. 27, n. 4, p. 372-391, 2008.

FISHER, Melissa. Wall Street women: professional saviors of the global economy. Critical perspectives on international business, v. 11, n. 2, p. 137-155, 2015.

INSCH, Gary S.; MCINTYRE, Nancy; NAPIER, Nancy K. "The expatriate glass ceiling: The second layer of glass". Journal of Business Ethics, v. 83, n. 1, p. 1928, 2008.

JANSSENS, Maddy; CAPPELLEN, Tineke; ZANONI, Patrizia. "Successful female expatriates as agents: Positioning oneself through gender, hierarchy, and culture". Journal of World Business, v. 41, n. 2, p. 133-148, 2006.

JOLY, Allain. "Alteridade: ser executivo no exterior". In: CHANLAT, Jean-Fran- 
çois (coord.) O Indivíduo na Organização: Dimensões Esquecidas. V. 1. 3. ed. São Paulo: Atlas, 2009.

JOVCHELOVICH, Sandra, BAUER, Martin. Entrevista Narrativa. BAUER, Martin W.; GASKELL, George. Pesquisa qualitativa com texto, imagem e som: um manual prático. Editora Vozes Limitada, 2017.

KOLLINGER, Iris. "Women and expatriate work opportunities in Austrian organizations". The International Journal of Human Resource Management, v. 16, n. 7, p. 1243-1260, 2005.

LEUZE, Kathrin.; STRAUß, Susanne. Why do occupations dominated by women pay less? How 'female-typical'work tasks and working-time arrangements affect the gender wage gap among higher education graduates. Work, Employment \& Society, p. 1-19, 2016.

MACHADO, Hilka Vier; HERNANDES, Cláudio Aurélio. "Alteridade, expatriação e trabalho: implicações para a gestão organizacional". RAC - Revista de Administração Contemporânea, v. 8, n. 3, p. 53-73, 2004.

NUNES, Ana Rita; CASACA, Sara Falcão. "As mulheres perante o desafio de uma carreira internacional”. Sociologia, problemas e práticas, n. 67, p. 77-94, 2015.

OLIVEIRA, Pedro Paulo de. A construção social da masculinidade. Belo Horizonte: Editora UFMG, 2004.

PEREIRA, Neuri Amabile Frigotto; PIMENTEL, Ricardo; KATO, Heitor Takashi. "Expatriação e Estratégia Internacional: o Papel da Familia como Fator de Equilíbrio na Adaptação do Expatriado". RAC - Revista de Administração Contemporânea, v. 9, n. 4, Out./Dez. 2005. p. 53-71.

POWELL, Abigail; BAGILHOLE, Barbara; DAINTY, Andrew. "How women engineers do and undo gender: consequences for gender equality". Gender, Work \& Organization, v. 16, n. 4, p. 411-428, 2009.

PRESTES, Vanessa Amaral; GRISCI, Carmem Ligia lochins; FRAGA, Aline Mendonça M. "Lifestyles of workers in the expatriation context". RAM - Revista de Administração Mackenzie (Online), v. 17, p. 39-59, 2016.

RODRIGUEZ, Jenny K.; SCURRY, Tracy. Career capital development of self-initiated expatriates in Qatar: cosmopolitan globetrotters, experts and outsiders. The International Journal of Human Resource Management, v. 25, n. 7, p. 1046-1067, 2014.

RODRIGUEZ, Jenny K.; RIDGWAY, Maranda. Contextualizing privilege and disadvantage: Lessons from women expatriates in the Middle East. Organization, 
p. 1-19, 2018.

ROLNIK, Suely. Toxicômanos de identidade: subjetividade em tempo de globalização. Cultura e subjetividade: saberes nômades. Campinas: Papirus, p. 19-24, 1997.

SCOTT, Joan Wallach. Gênero: uma Categoria Útil de Análise Histórica. In: Educação e Realidade, v.20, n.2, julho/ dezembro 1995.

SHORTLAND, Susan. Women expatriates: a research history. Research Handbook on Women in International Management, Edward Elgar, Cheltenham, p. 18-44, 2014.

SELMER, Jan; LEUNG, Alicia. S. M. "Are Corporate Career Development Activities Les Available to Female Than to Male Expatriates?" Journal of Business Ethics, v. 43, n. 1-2, p. 125-136, 2003 a.

"Personal characteristics of female vs male business expatriates". International Journal of Cross Cultural Management, v. 3, n. 2, p. 195-212, 2003b.

TUNG, Rosalie L. "Wanted: A Person for All Seasons: An Examination of Managerial Skills and Core Competencies for the Twenty-first Century". Paper presented at the 55th Annual Meetings of the Academy of Management, (August 6-9) Vancouver, 1995a.

"Women in a Changing Global Economy". Paper presented at the 10th Annual Conference of the Society of Industrial/Organizational Psychology, (May 17-20), Orlando, Florida, 1995 b.

"Female expatriates: The model global manager?" Organizational Dynamics, v. 33, n. 3, p. 243-253, 2004.

WATTS, Jacqueline H. “'Allowed into a Man's World' Meanings of Work-Life Balance: Perspectives of Women Civil Engineers as 'Minority' Workers in Construction”. Gender, Work \& Organization, v. 16, n. 1, p. 37-57, 2009.

Recebido em abril de 2019.

Aprovado em agosto de 2019. 